\title{
Caregivers and the Family
}

\section{P 093 THE BURDEN OF END OF LIFE CARE-PROMOTING THE PSYCHOLOGICAL RECOVERY OF INFORMAL CARE GIVERS}

Michelle Brown, Martin Brock. University of Derby, Chesterfield, United Kingdom

\subsection{6/bmjspcare-2014-000654.134}

Background The National End of Life Programme (DOH 2010) has set out a direction of travel for social care at the end of life and important targets include commissioning and delivery of person centred and integrated care for both patients care givers and families.

From the point of view of care giving the burden is likely to increase as there will likely be fewer carers and more people dying at home with complex care needs (Seale 2000)

Carers are a valuable part of care delivery in the UK and valuing and supporting them with compassionate philosophy should be a key strategy (Brown 2012) yet the Health Care Commission in 2008 found that the most consistent complaint from caregivers was related to end of life care.

There is a body of research describing the adverse effects of care giving including stress, anxiety and mortality (Gaugler et al 2004).

Integrating relative and family in end of life care decisions and increasing understanding of the end of life process appears to be beneficial for both the patient experience and the psychological recovery of the relatives (Schulz et al 2003).

Aims Improve psychological recovery of informal care givers Facilitate informal care givers' awareness of the end of life process Assist informal care givers in developing self-compassion and coping strategies

Framework: Development of a 6 week psycho-educational support group for informal care givers either during or post end of life care
Format of group will include educational components and peer support activities.

Group Facilitated by Palliative Care Expert \& CBT Psychotherapist.

Conclusion Considering the increase of care giving at home, including end of life, informal caregivers require more comprehensive support than currently available to enable their psychological recovery.

Increasing awareness of the end of life process and development of self-compassion is likely to enable this recovery. 